\title{
ON UNICITY OF MEROMORPHIC FUNCTION AND ITS $k$ TH ORDER DERIVATIVE
}

\author{
CHAO MENG
}

\begin{abstract}
In this paper, we study the uniqueness problems on meromorphic function and its $k$ th order derivative. The results in this paper improve the results given by K. W. Yu (On entire and meromorphic functions that share small functions with their derivatives, J. Inequal. Pure Appl. Math. 4(1)(2003), Art. 21), L. P. Liu and Y. X. Gu (Uniqueness of meromorphic functions that share one small function with their derivatives, Kodai Math. J. 27(2004), 272-279) and supplement a result of S. H. Lin and W. C. Lin (Uniqueness of meromorphic functions concerning weakly weighted sharing, Kodai Math. J. 29(2006), 269-280).
\end{abstract}

Mathematics subject classification (2010): 30D35.

Keywords and phrases: unicity, meromorphic function, small function.

\section{REFERENCES}

[1] A. BANERJEE, On uniqueness of meromorphic functions when two differential monomials share one value, Bull. Korean Math. Soc., 44, 4 (2007), 607-622.

[2] A. BANERJEe AND S. MUKHERJEE, Uniqueness of meromorphic functions concerning differential monomial sharing the same value, Bull. Math. Soc. Sci. Math. Roumanie, 50 (2007), 191-206.

[3] R. BRÜCK, On entire functions which share one value CM with their first derivative, Results Math., 30 (1996), 21-24.

[4] Z.X. ChEN AND K.H. SHON, On conjecture of R.Bruck concering the entire function sharing one value CM with its derivatives, Taiwanese J. Math., 8 (2004), 235-244.

[5] G.G. Gundersen, Meromorphic functions that share finite values with their derivatives, J. Math. Anal. Appl., 75 (1980), 441-446. Correction, 86 (1982), 307.

[6] G.G. GUNDERSEN AND L.Z. YANG, Entire functions that share one vlaue with one or two of their derivatives, J. Math. Anal. Appl., 223 (1998), 88-95.

[7] W.K. HaYman, Meromorphic Functions, Clarendon, Oxford, 1964.

[8] I. LAHIRI, Weighted value sharing and uniqueness of meromorphic functions, Complex Variables Theory Appl., 46 (2001), 241-253.

[9] I. LAHIRI AND S. DEWAN, Inequealities arising out of the value distribution of a differential monomial, J. Inequal.Pure Appl. Math., 4 (2003), Art. 27.

[10] S.H. LIN AND W.C. LIN, Uniqueness of meromorphic functions concerning weakly weighted sharing, Kodai Math. J., 29 (2006), 269-280.

[11] L.P. LIU AND Y.X. GU, Uniqueness of meromorphic functions that share one small function with their derivatives, Kodai Math. J., 27 (2004), 272-279.

[12] L.A. RubEL AND C.C. YANG, Values shared by an entire function and its derivatives, In: Complex Analysis, Kentucky 1976 (Proc. Conf), Lecture Notes in Mathematics, Vol. 599, Springer-Verlag, Berlin, 1977, 101-103.

[13] L.Z. YANG, Entire functions that share finite values with their derivatives, Bull. Austral. Math. Soc., 41 (1990), 337-342.

[14] L.Z. YANG, Solution of a differential equation and its applications, Kodai Math. J., 22 (1999), 458464.

[15] L. YANG, Value distribution theory, Springer-Verlag, Berlin, 1993. 
[16] K.W. YU, On entire and meromorphic functions that share small functions with their derivatives, J. Inequal. Pure Appl. Math., 4, 1 (2003), Art. 21.

[17] Q.C. ZHANG, Meromorphic function that share one small function with its derivative, J. Inequal. Pure Appl. Math., 6, 4 (2005), Art.116. 